\title{
Protan color vision deficiency with a unique order of green-red as the first two genes of a visual pigment array
}

\author{
Hisao Ueyama $\cdot$ Shoko Tanabe $\cdot$ Sanae Muraki-Oda $\cdot$ \\ Shinichi Yamade $\cdot$ Iwao Ohkubo
}

Received: 5 March 2006/ Accepted: 2 May 2006/ Published online: 28 July 2006

(C) The Japan Society of Human Genetics and Springer-Verlag 2006

\begin{abstract}
Normal visual pigment gene arrays on the human X chromosome have a red gene at the first and a green gene at the second positions. More than half of the arrays have additional green genes downstream, but only the first two genes of the array are likely to be expressed in the retina. An array consisting of four genes in two Japanese participants, A121 and A447, was detected either by pulsed field gel electrophoresis and subsequent Southern hybridization or by single nucleotide primer extension reaction. In both participants, the first gene of the array was green, downstream genes were red and green, and the fourth gene was green. The red gene was determined to be at the second position by comparison of polymorphic sites among the intergenic regions that had been amplified by long-range PCR. Such an array with a reverse normal order of pigment genes, green-red as the first two, has never been reported before. They were expected to have normal color vision but showed protan deficiency (protanomaly), a phenotype lacking the red pigment. The red gene had no mutations in the exons and exon/intron boundaries, but had an A-71C substitution in the promoter in both participants.
\end{abstract}

H. Ueyama $(\bowtie) \cdot$ I. Ohkubo

Department of Biochemistry and Molecular Biology,

Shiga University of Medical Science, Seta,

Otsu 520-2192, Japan

e-mail: datt@belle.shiga-med.ac.jp

S. Tanabe

Institute of Vision Research, 12-23 Sanbonmatsu-cho,

Atsuta-ku, Nagoya 456-0032, Japan

S. Muraki-Oda $\cdot$ S. Yamade

Department of Ophthalmology, Shiga University of Medical

Science, Seta, Otsu 520-2192, Japan
Keywords Visual pigment - Cone opsin gene ·

Congenital red/green color vision deficiency ·

Protan deficiency $\cdot$ Long-range PCR $\cdot$ Pulsed field gel electrophoresis $\cdot$ Promoter

\section{Introduction}

The red/green visual pigment gene arrays on the human X chromosome often have three or more genes (Nathans et al. 1986b), but only the first two are likely to be expressed in the retina (Hayashi et al. 1999). The red gene is at the first and a green gene is at the second position in color-normal males (Nathans et al. 1986b; Vollrath et al. 1988; Hayashi et al. 2001) and referred to as red-green in our study. The terms "red" and "green" are used relative to exon 5, because most of the spectral peak differences between red and green pigments are due to the difference in the two amino acids encoded by the exon (Merbs and Nathans 1992; Asenjo et al. 1994). The red type exon 5 has TAC for Tyr at codon 277 and ACC for Thr at codon 285, while the green type exon 5 has TTC for Phe at codon 277 and GCC for Ala at codon 285.

In congenital color vision deficiency the gene arrays are different from the "red-green" in color-normals. Gene arrays are either a single green or green-green in the protan deficiency, in which the red pigment is lacking (Nathans et al. 1986b; Deeb et al. 1992; Ueyama et al. 2004a). The single green array causes dichromacy (protanopia), in which only green and blue pigments are present. The green-green array causes dichromacy or anomalous trichromacy (protanomaly), in which two spectrally different green pigments in addition to blue pigment are present, depending on the 
differences in exons 2,3 , and 4 of the two green genes (Deeb et al. 1992; Ueyama et al. 2004a). In the deutan deficiency, in which the green pigment is lacking, gene arrays are either a single red or red-red (Nathans et al. 1986b; Deeb et al. 1992). The single red array causes dichromacy (deuteranopia), in which only red and blue pigments are present. The red-red array causes dichromacy or anomalous trichromacy (deuteranomaly), in which two spectrally different red pigments in addition to blue pigment are present, depending on the differences in exons 2, 3, and 4 of the two red genes (Deeb et al. 1992).

In previous studies, we have analyzed gene arrays of 125 Japanese male participants with protan deficiency (Ueyama et al. 2004a). In this population 9 participants had a red gene in addition to a green gene or genes. Detailed analysis showed that the red gene was present at the first position in 7 of the 9 participants, which meant that these 7 participants had an apparently normal red-green array. The other two participants, A121 and A447, had the red gene downstream (Ueyama et al. 2004a). In this study, we determined the position of the red gene in the array of participants A121 and A447.

\section{Materials and methods}

\section{Human participants}

One participant, A121, aged 19 years, consulted for his color vision at Japan Red Cross Nagoya First Hospital and the other, A447, aged 16 years, consulted for his color vision at Shiga University of Medical Science Hospital. They were diagnosed as protanomaly by examination with an anomaloscope (model I; Schmidt and Haensch, Berlin, Germany), as well as other clinical tests shown in Table 1 . They had no ocular diseases. Color-normal male participants, N1, N2, N10, N11, N22, and N101, and a male deuteranopic participant, A493, also participated in this study. A blood sample was drawn from each participant for extraction of genomic DNA. Informed consent was obtained from all study participants and procedures were conducted according to the Declaration of Helsinki. This study was approved by the Medical Ethics Committee at Shiga University of Medical Science (no. 13-6).

Pulsed field gel electrophoresis

Peripheral blood leukocytes were embedded in $0.75 \%$ agarose gel plugs using the CHEF Genomic DNA Plug Kit (Bio-Rad, Hercules, CA, USA). The gel plugs were treated with proteinase $\mathrm{K}$ and then with phenylmethylsulfonylfluoride in accordance with the manufacturer's instructions. The genomic DNA in gel plugs was digested with NotI (Takara Shuzo, Kyoto, Japan) at 30 units/plug overnight at $37^{\circ} \mathrm{C}$ and subjected to $1 \%$ agarose gel electrophoresis in an LKB 2015 Pulsaphor Electrophoresis Unit (LKB-Pharmacia, Bromma, Sweden) using a 25 -s pulse at $150 \mathrm{~V}$ for $20 \mathrm{~h}$ at $14^{\circ} \mathrm{C}$. DNA size markers were the Promega Markers Lambda Ladders (Promega, Madison, WI, USA). After electrophoresis, the gel was blotted to a nylon membrane (HyBond-XL; Amersham Pharmacia Biotech, Little Chalfont, Buckinghamshire, UK) and the membrane was subjected to hybridization with ${ }^{32} \mathrm{P}$-labeled human green opsin cDNA (50 ng). After washing, the membrane was exposed to an X-ray film (RX; Fuji Photo Film, Minamiashigara, Japan) at room temperature for $24 \mathrm{~h}$ with an intensifying screen.

Single nucleotide primer extension reaction

The PCR products for promoter and exons $2-5$ from the genomic DNA were purified from the agarose gel with the Sephaglas BandPrep Kit (Amersham Biosciences, Piscataway, NJ, USA) and subjected to the single nucleotide primer extension reaction using the ABI PRISM SNaPshot Multiplex Kit (Applied Biosystems, Foster City, CA, USA) in accordance with the manufacturer's instructions. The primers are listed in Table 2. The nucleotides to be detected are shown in Table 3. In this method, primers correspond to the region immediately upstream (or downstream) of the position of interest, i.e., a position with differences in nucleotides either between the first gene promoter and downstream gene promoters, or between red type

Table 1 Clinical tests used for analysis of color vision status

\begin{tabular}{llllllll}
\hline Participant & Match range & Ishihara plates & SPP-1 & HRR plates & TMC plates & Panel D-15 test & Lantern test \\
\hline A121 & $60-64$ & $11 / 12$ & $8 / 10$ & Mild & $5 / 5$ & Pass & $3 / 9$ \\
A447 & $56-58$ & $16 / 16$ & $9 / 10$ & Mild & $5 / 5$ & Pass & $7 / 9$ \\
\hline
\end{tabular}

Denominators are numbers of plates or lights examined, and numerators are numbers of failed plates or lights

SPP-1 standard pseudoisochromatic plates-1, HRR Hardy, Rand, and Ritter, TMC Tokyo Medical College 
Table 2 Primers used in primer extension reaction or long-range, second round, and conventional polymerase chain reaction (PCR)

${ }^{a}$ Nucleotide numbers are from the NCBI Nucleotide Database (NT_025965)

\begin{tabular}{|c|c|c|}
\hline Primer & Nucleotide sequence $\left(5^{\prime} \rightarrow 3^{\prime}\right)$ & Position \\
\hline \multicolumn{3}{|c|}{ For primer extension reaction } \\
\hline PEPF & CGGGCTGATCCCAC & For -36 \\
\hline PE2R & ATTTGTGAAGACGGATGCA & Exon 2 , for codon $65-2$ \\
\hline PE3R & GGGGCTGTCCACACAGCAG & Exon 3, for codon $180-1$ \\
\hline PE4F & ATGGTCACCTGCTGCATCA & Exon 4 , for codon $230-2$ \\
\hline PE5R & AAAGCATGCGAAGAAGG & Exon 5 , for codon $285-1$ \\
\hline \multicolumn{3}{|c|}{ For long-range PCR } \\
\hline FG & GAGGCGAGGCTACGGAGT & -819 to -802 (first gene promoter) \\
\hline BG5 & ATTCTGGATGGAAGGGTCTTT & $788461-788441^{\mathrm{a}}$ \\
\hline BG9 & TCCGTGGGTTTGCCTCTTCTG & $789730-789710^{\mathrm{a}}$ \\
\hline DG17 & GAGCAGTTTAGGCGGTGAGTG & $784055-784075,{ }^{a} 821184-821204^{a}$ \\
\hline $5 \mathrm{RR}$ & GCAGTACGCAAAGATCATCACC & Red type exon 5 \\
\hline $5 \mathrm{RF}$ & GGTGATGATCTTTGCGTACTGCG & Red type exon 5 \\
\hline PDR & CCTGAGGGTCACGGTGCTTTA & -7 to -27 (downstream gene promoter) \\
\hline $5 \mathrm{GR}$ & GAAGCAGAATGCCAGGAC & Green type exon 5 \\
\hline DG4 & AGACAGAGTCTTGGTCTGTTG & -317 to -297 (downstream gene promoter) \\
\hline S4 & ATGCCTCCTGGGTTTGTCATT & $T E X 28$ gene intron $3,857612-857592^{a}$ \\
\hline $\mathrm{P}-71 \mathrm{C}$ & GGCСТCTTCACCTTAAAAGCG & -51 to -71 , specific for $-71 \mathrm{C}$ \\
\hline S15 & CCGCTTCCAAAAGAATAAAAG & $786910-786930,{ }^{a} 824039-824059^{a}$ \\
\hline $6 \mathrm{MR}$ & AAAGCTGCAAGATGCAGTTTT & Exon 6, specific for R330Q mutation \\
\hline \multicolumn{3}{|c|}{ For second round or conventional PCR } \\
\hline DG13 & GAGAGGCAGAAGGACATTAGA & $784872-784892,{ }^{\mathrm{a}} 822001-822021^{\mathrm{a}}$ \\
\hline BG1 & GGAAGGCAGAAGGGCAAGAGG & $785965-785945,{ }^{a} 823094-823074^{a}$ \\
\hline S16 & CTCCGTCTCCCCTTTCTGTCA & $787288-787308,{ }^{a} 824417-824437^{a}$ \\
\hline BG4 & GGGTTGCTGGGACATCTT & $787878-787861,{ }^{\mathrm{a}} 825007-824490^{\mathrm{a}}$ \\
\hline S18 & ACTCGGGCTACAAAGGTGAAG & $787899-787919,{ }^{a} 825028-825048^{a}$ \\
\hline S12 & ACTCCAGCGGAAGCAGTCACA & $788530-788550,{ }^{a} 825659-825679^{a}$ \\
\hline $5 \mathrm{GF}$ & GTGATGGTCCTGGCATTCTGCT & Green type exon 5 \\
\hline I5R & ACGGTATTTTGAGTGGGATCTGCT & Intron 5 \\
\hline $4 \mathrm{RF}$ & TGCATCATCCCACTCGCT & Red type exon 4 \\
\hline
\end{tabular}

Table 3 Estimation of red/green gene number in A121 by single nucleotide primer extension

\begin{tabular}{lllllll}
\hline Gene number $^{\mathrm{a}}$ & Participant & Promoter (T/A) & Exon 2 (A/G) & Exon 3 (C/A) & Exon 4 (C/T) & Exon 5 (C/T) \\
\hline 2 & N11 & $0.49 \pm 0.02$ & $0.41 \pm 0.04$ & $0.45 \pm 0.03$ & $0.87 \pm 0.09$ & $0.37 \pm 0.07$ \\
3 & N10 & $0.82 \pm 0.03$ & $0.68 \pm 0.05$ & $0.76 \pm 0.05$ & $1.55 \pm 0.16$ & $0.64 \pm 0.04$ \\
& N22 & $0.86 \pm 0.03$ & $0.71 \pm 0.01$ & $0.81 \pm 0.02$ & $1.56 \pm 0.07$ & $0.18 \pm 0.01^{\mathrm{d}}$ \\
4 & N2 & $1.47 \pm 0.08$ & $1.06 \pm 0.15$ & $1.10 \pm 0.03$ & $2.44 \pm 0.21$ & $0.93 \pm 0.04$ \\
& N101 & $1.32 \pm 0.21$ & $1.02 \pm 0.09$ & $0.49 \pm 0.04^{\mathrm{c}}$ & $2.11 \pm 0.06$ & $0.86 \pm 0.03$ \\
5 & A447 & $1.56 \pm 0.11$ & $1.08 \pm 0.18$ & NA & $2.40 \pm 0.14$ & $0.94 \pm 0.17$ \\
& N1 & $1.75 \pm 0.58$ & $0.59 \pm 0.09^{\mathrm{b}}$ & $1.52 \pm 0.02$ & $3.18 \pm 0.32$ & $1.15 \pm 0.03$ \\
\hline & A121 & $1.20 \pm 0.06$ & $0.91 \pm 0.02$ & $1.11 \pm 0.20$ & $2.30 \pm 0.30$ & $0.86 \pm 0.05$ \\
\hline
\end{tabular}

Values are ratios of peak fluorescent areas in average \pm standard deviation from 3 to 5 independent experiments

$N A$ not applicable, because A447 had green exon 3 (codon 180 was for Ala) only

${ }^{a}$ Gene number was estimated by pulsed field gel electrophoresis and subsequent Southern hybridization

${ }^{\mathrm{b}}$ Expected red:green ratio was 2:3

${ }^{\mathrm{c}}$ Expected red:green ratio was 2:2

${ }^{\mathrm{d}}$ Expected red:green ratio was 2:1

and green type exons. The primer extension products were analyzed in the ABI PRISM 310 Genetic Analyzer (Applied Biosystems) using a POP-4 polymer. Nucleotide peak fluorescent areas were compared using GeneScan Analysis Software (version 3.1; Applied Biosystems).
Conventional PCR, long-range PCR, and subsequent analysis

Promoter and exons 1-6, including their flanking introns, were each amplified as described (Ueyama et al. 2003). Long-range PCR for the first gene, downstream 
genes, and the furthest downstream gene was performed as described (Oda et al. 2003; Ueyama et al. 2004a).

In this study the regions amplified by long-range PCR were expanded upstream and/or downstream. The primers used are listed in Table 2 and the strategies are depicted in Fig. 1. Pulsed field gel electrophoresis was applied to the long-range PCR products for validation of sizes. The conditions were the same as in the previous section except pulse time; a 1-s pulse was used.

The long-range PCR products were used as the template in the second round PCR for the overlapped portion of the intergenic regions and for promoters, exons, and exon/intron boundaries. The primers used in the second round PCR are listed in Table 2. Combinations of primers in the PCR for the overlapped portion were as follows: DG13 and BG1 for polymorphic sites 1 and 2, S16 and BG4 for site 3, S18 and BG5 for sites $4-6$, and S12 and BG9 for sites 710. Exons 2-4 contained in F-D1, F-D2, R-U, and G-U were classified into the red and green types. Red type exon 2 had ACT for Thr at codon 65 and TCT for Ser at codon 116. Green type exon 2 had ATT for Ile at codon 65 and TAT for Tyr at codon 116. Red type exon 3 had TCT for Ser at codon 180 and green type exon 3 had GCT for Ala at codon 180. Red type exon 4 had ATC for Ile at codon 230 and GCT for Ala at codon 233. Green type exon 4 had ACC for Thr at codon 230 and AGC for Ser at codon 233. TaKaRa Taq DNA polymerase (Takara Shuzo) was used for the second round PCR. The PCR products were subjected to sequencing in the ABI PRISM 310 Genetic Analyzer using the DYEnamic ET Terminator Cycle Sequencing Kit (Amersham Pharmacia Biotech).
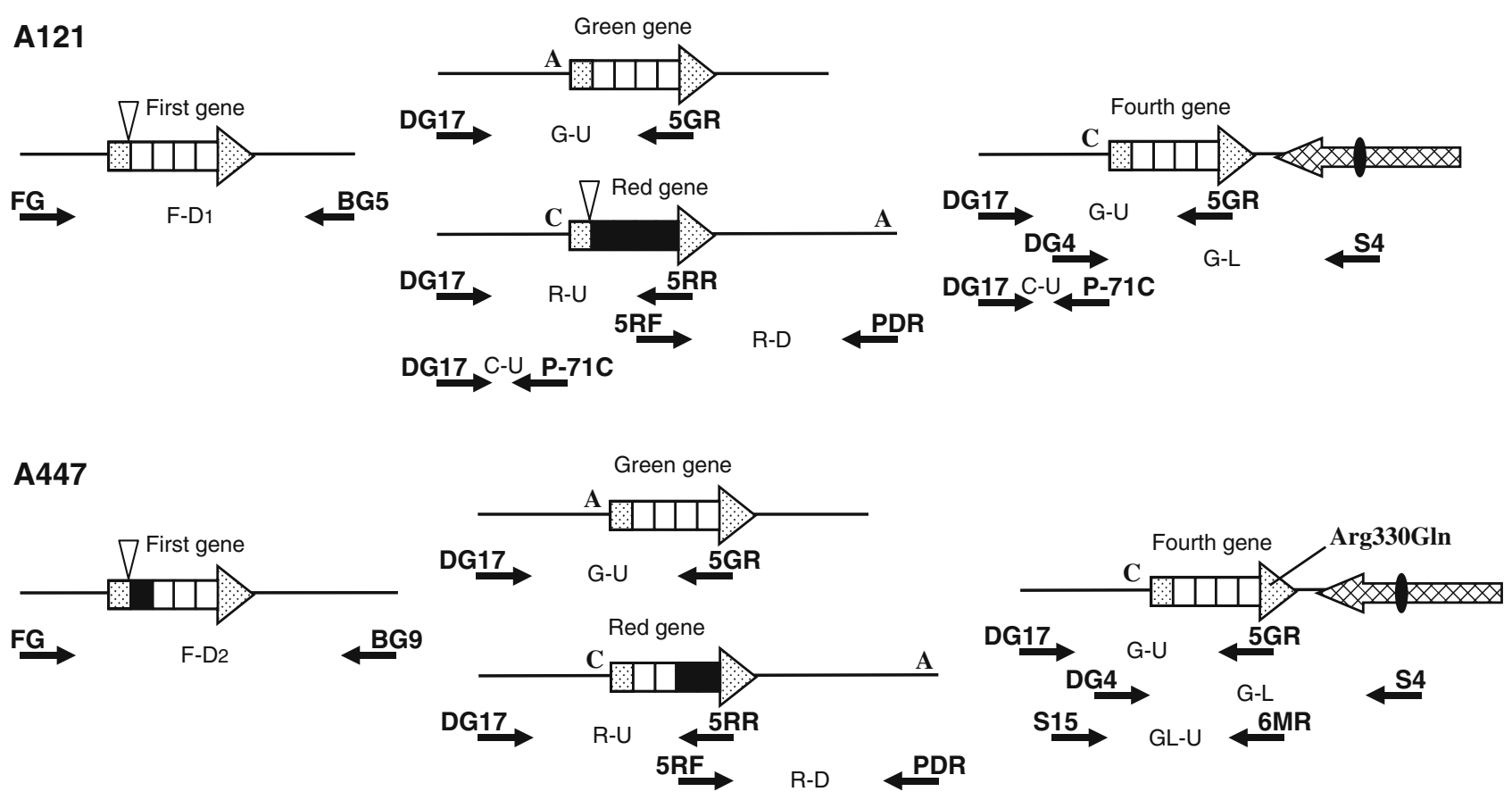

Fig. 1 Long-range polymerase chain reaction (PCR) strategy. The first gene was amplified with primers FG and BG5 in A121 and with primers FG and BG9 in A447. The product was designated $F-D$ for first downstream $\left(F-D_{1}\right.$ in $\mathrm{A} 121$ and $F-D_{2}$ in A447). The upstream region of the red gene was amplified with primers DG17 and 5RR. The product was designated $R-U$ for red upstream. The 1,284-bp insert (adapted from Meagher et al. 1996) in intron 1 is indicated by an inverted triangle. Downstream region of the red gene was amplified with primers $5 \mathrm{RF}$ and PDR. The product was designated $R-D$ for red downstream. The upstream region of the downstream green genes was amplified with primers DG17 and 5GR. The product was designated $G-U$ for green upstream. The furthest downstream (fourth) green gene was amplified with primers DG4 and S4. The product was designated $G$ - $L$ for green last. In A121, upstream region of the promoter with $-71 \mathrm{C}$ was amplified with primers DG17 and $\mathrm{P}-$ 71C. The product was designated $C-U$ for $-71 C$-upstream. In A447, upstream region of the fourth gene was amplified with primers S15 and $6 \mathrm{MR}$. The product was designated $G L-U$ for green last upstream. These long-range PCR products were used as the template in the second round PCR for the overlapped portion of the intergenic regions, as well as for promoters, exons, and exon/intron boundaries. $A$ and $C$ on bars are nucleotides at 71. Dotted boxes represent exon 1, dotted arrowheads represent exon 6, closed boxes represent red type exons 2-5, and open boxes represent green type exons 2-5. Criss-crossed arrows represent the functional TEX 28 gene and closed circles represent the 697-bp insert in intron 3 (adapted from Ueyama et al. 2004b) 


\section{Results}

Clinical data

On the basis of match ranges of 60-64 in A121 and 56-58 in A447 (Table 1) after examination by anomaloscopy, both participants were classified into protanomaly, a mild type of protan deficiency. The other tests documenting color vision deficiency are shown in Table 1.

\section{Determination of gene number}

Our previous study (Ueyama et al. 2004a) showed that the first gene was green, the downstream genes were red and green, and the furthest downstream gene was green in A121. The same results were obtained in A447 (data not shown).

Detailed gene analysis began by determining the red/green gene number. The most reliable method for this purpose is pulsed field gel electrophoresis, followed by Southern hybridization (Macke and Nathans 1997). Participant A447 was analyzed by this method because a gel plug was available. An array consisting of four genes was detected in A447 (Fig. 2). Evidence that A121 also had a four-gene array was circumstantial. Promoter and exons 2, 3, 4, and 5 were amplified from the genomic DNA by PCR using the previously reported primers (Ueyama et al. 2003) and the products were subjected to a single nucleotide primer extension reaction. Typical electropherograms are shown in Fig. 3. From the results summarized in Table 3, the red/green gene number in A121 was presumed to be 4 or 5 from the analysis of promoter, and the ratio of red type nucleotide:green type nucleotide was presumed to be 1:3 in exons 3, 4, and 5. The

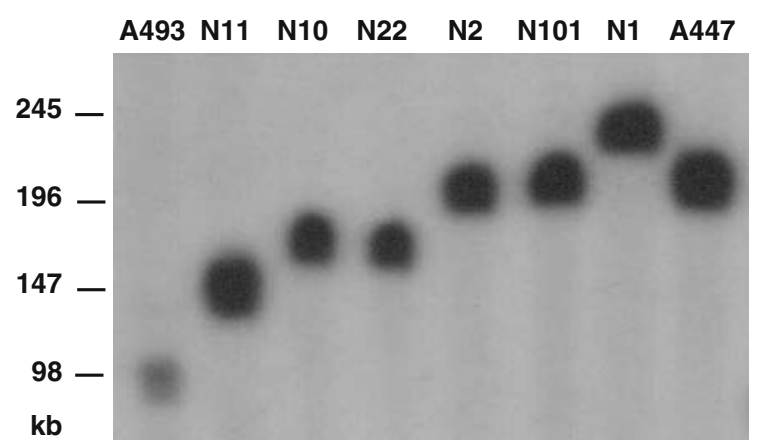

Fig. 2 Estimation of red/green gene number by pulsed field gel electrophoresis and subsequent Southern hybridization. The red/ green gene number was estimated to be 1 in participant A493, 2 in N11, 3 in N10 and N22, 4 in N2 and N101, 5 in N1, and 4 in A 447 combined results indicated that A121 also had a fourgene array.

Gene structure and gene order

To determine the position of the red gene, the intergenic regions were amplified by long-range PCR, using the strategy shown in Fig. 1. In both participants, the 697-bp insert (Ueyama et al. 2004b) was undetectable in the intergenic regions, which are occupied by nonfunctional TEX28 genes, but was present in the functional TEX28 gene, which exists immediately downstream of the array. By using primer S4 specifically for the insert, we could also amplify the whole of the fourth gene. Typical profiles of these long-range PCR products in pulsed field gel electrophoresis are shown in Fig. 4. All of the products had the expected sizes. A typical electrophoretic profile of G-L has been previously reported (Ueyama et al. 2004b).

The structure of each gene is also shown in Fig. 1. In A121, exons 2-4 of the three green genes were of the green type, while exons 2-4 of the red gene were of the red type. The red gene promoter had $-71 \mathrm{C}$ and the two downstream green genes had $-71 \mathrm{~A}$ and $-71 \mathrm{C}$. Since the promoter of the green gene at the fourth position had $71 \mathrm{C}$, the other downstream green gene was presumed to have $-71 \mathrm{~A}$. At this point the red gene was thought not to be at the third position, because the gene immediately downstream of the red gene had -71A, but the fourth gene had $-71 \mathrm{C}$. The red gene had the 1,284-bp insert in intron 1 , which is usually found in the gene at the first position (Meagher et al. 1996).

In $\mathrm{A} 447$, the green gene at the first position had exon 2 of the red type, while the two downstream green

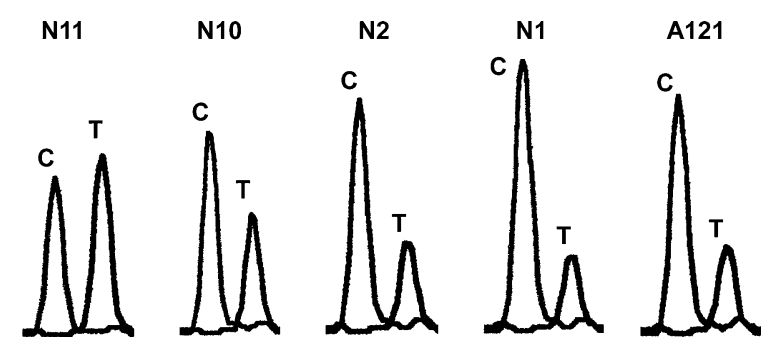

Fig. 3 Typical electropherograms in the single nucleotide primer extension method. The products by PCR for exon 4 were purified and subjected to the single nucleotide primer extension reaction using primer PE4F. The position for detection was codon 230-2 in exon 4 ( $T$ in the red type exon 4 and $C$ in the green type exon 4). The products were loaded onto the ABI PRISM 310 Genetic Analyzer and peak fluorescent areas of the nucleotides measured using GeneScan Analysis Software were compared. The fluorescence ratio of $\mathrm{C} / \mathrm{T}$ was 0.80 in participantN11 with a two-gene array, 1.54 in N10 with a three-gene array, 2.38 in N2 with a fourgene array, 3.09 in N1 with a five-gene array, and 2.28 in A121 


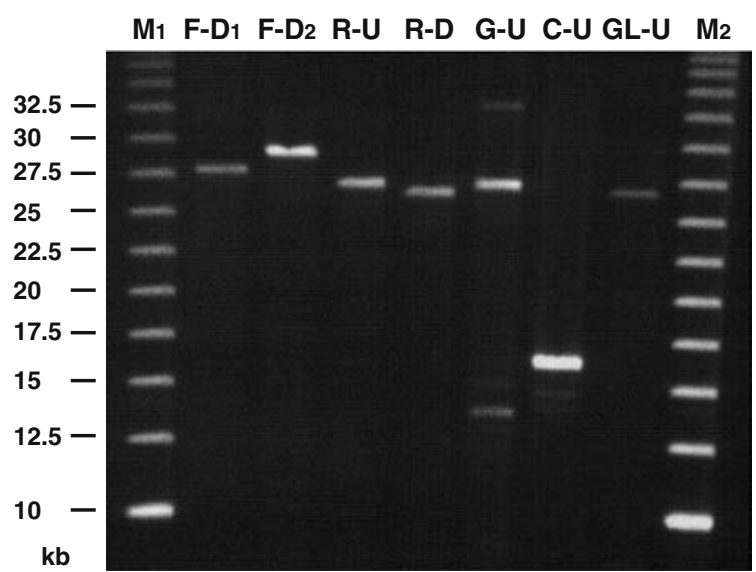

Fig. 4 Long-range PCR products. A 5- $\mu$ l sample of the $25-\mu 1$ PCR reaction mixture was analyzed by pulsed field gel electrophoresis. $\mathrm{M}_{1}$ and $\mathrm{M}_{2}, 2.5-\mathrm{kb}$ ladder markers (Takara Shuzo), $100 \mathrm{ng}$ in $\mathrm{M}_{1}$ and $200 \mathrm{ng}$ in M2; F-D1, first gene with its downstream region $(27,601 \mathrm{bp}$, according to the NCBI Nucleotide Database, NT_025965) in A121; F-D2, first gene with its downstream region $(28,870 \mathrm{bp})$ in A447; R-U, upstream region of the red exon 5 (26,897 or $26,886 \mathrm{bp})$ in A447; R-D, from the red exon 5 to the promoter immediately downstream of the red gene $(26,283$ or $26,271 \mathrm{bp})$ in $\mathrm{A} 447$; G-U, upstream regions of the downstream green exon $5(26,900$ or $26,889 \mathrm{bp})$ in A447; C$\mathrm{U}$, upstream regions of $-71 \mathrm{C}(15,984$ or $15,973 \mathrm{bp})$ in A121; GL$\mathrm{U}$, upstream region of exon 6 with the mutation of Arg330Gln $(\mathrm{CGA} \rightarrow \mathrm{CAA} ; 26,499$ or $26,488 \mathrm{bp}$ ) in A447

genes had exon 2 of the green type. In the red gene, exons 2 and 3 were of the green type, although exon 4 , as well as exon 5, was of the red type. The red gene had $-71 \mathrm{C}$ and the two downstream green genes had $-71 \mathrm{~A}$ and $-71 \mathrm{C}$. Since the green gene at the fourth position had $-71 \mathrm{C}$, the other downstream green gene was presumed to have $-71 \mathrm{~A}$. The red gene was thought not to be at the third position because the gene immediately downstream of the red gene had $-71 \mathrm{~A}$, but the fourth gene had $-71 \mathrm{C}$. The green gene at the fourth position had a mutation in exon 6 (CGA $\rightarrow$ CAA, Arg330Gln), which was the same mutation reported in a deutan subject (Ueyama et al. 2002). Exon 6 of the two downstream green genes was amplified using the PCR amplified downstream genes as the template. The primers used in this second round of PCR were 5GF and E6R (Table 2). The amplified exon 6 had both CGA and CAA at codon 330. Therefore, the other downstream green gene was presumed to have normal CGA at this codon.

The 1:3 ratio obtained from these analyses of red type:green type in exons 2, 3, 4, and 5 in A121 and in exons 2, 4, and 5 in A447 (Fig. 1) was consistent with that from the single nucleotide primer extension reaction (Table 2).

We found ten polymorphic sites in the overlapped portion (at most 5,676 bp) of the intergenic regions that had been amplified by long-range PCR. The simple numbers represent positions in the NCBI Nucleotide Database, NT_025965, and rs and JST numbers represent those in the NCBI SNP and JSP Databases respectively: site 1,785606 and 822735 for $\mathrm{C} / \mathrm{G}$; site 2 , 785812 and 822941 for G/T; site 3, 787701 and 824830 for $\mathrm{C} / \mathrm{G}$; site 4 (rs2239465, JST010613), 788239 and 825368 for G/T; site 5, 788266 and 825395 for $\mathrm{A} / \mathrm{G}$; site 6 (rs929001, JST010614), 788367 and 825496 for A/C; site 7, 788676 and 825805 for G/T; site 8 (rs1018785), 788712 and 825841 for G/T; site 9, 788956 and 826088 for A/G; site 10 (rs2315055), 789540 and 826666 for A/ G. In addition to these sites we also checked possible polymorphic sites as in the following, but found no differences in the two participants: $\mathrm{C} / \mathrm{T}$ at 787548 and 824677, C/G at 788317 and 825446 (rs5987232), C/T at 788588 and 825717 (rs6643829), and $\mathrm{C} / \mathrm{T}$ at 789406 and 826532 (rs5989616).

Nucleotide sequences among the intergenic regions contained in F-D1 or F-D2, R-U, G-U, R-D, and C-U or GL-U are compared and summarized in Fig. 5. Although G-U in both participants and C-U in A121 were each derived from two regions, comparison of the polymorphic sites led to one possible interpretation of gene order (Fig. 5).

In A121, site 1 showed no differences, but the other nine sites were informative. The nucleotides at sites 27 were $\mathrm{T}, \mathrm{C}, \mathrm{G}, \mathrm{A}, \mathrm{A}$, and $\mathrm{G}$, and those at sites 9 and 10 were $\mathrm{G}$ and $\mathrm{A}$ in $\mathrm{C}-\mathrm{U}$, which was in contrast to R-D where $G, G, T, G, C$, and $T$ were at sites $2-7$, and A and $G$ were at sites 9 and 10 (Fig. 5). The results confirmed that the red gene was present not at the third position, but at the second position. The gene array in A121 was thus determined to be green-redgreen-green.

In A447, sites 2 and 10 showed no difference, but the other eight sites were informative. The nucleotide at site 8 in F-D2 was T, which was in contrast to G-U where $\mathrm{G}$ was at site 8 (Fig. 5), indicating that neither of the green genes occupied the second position. Moreover, the nucleotides at sites 3-7 were G, T, G, C, and $\mathrm{T}$, and that at site 9 was $\mathrm{A}$ in $\mathrm{R}-\mathrm{D}$, which was in contrast to GL-U where C, G, A, A, and G were at sites 37 and $\mathrm{G}$ was at site 9 (Fig. 5). These results confirmed that the red gene was present not at the third position, but at the second position. The gene array in A447 was thus determined to be green-red-green-green.

Integrity of the red gene

Since some color vision deficiencies may be caused by a nucleotide substitution or deletion (Winderickx et al. 1992; Ueyama et al. 2002, 2004a), the integrity of the 
Fig. 5 Determination of gene order. Nucleotide sequences were compared among overlapped portions of the intergenic regions that had been amplified by long-range PCR. Nucleotides are ten polymorphic sites (sites 1-10, from left to right). In F-D1, sites 1-6 only could be analyzed, and in GL-U, sites $3-10$ only could be analyzed. Boxes represent visual pigment genes and vertical bars inside represent six exons
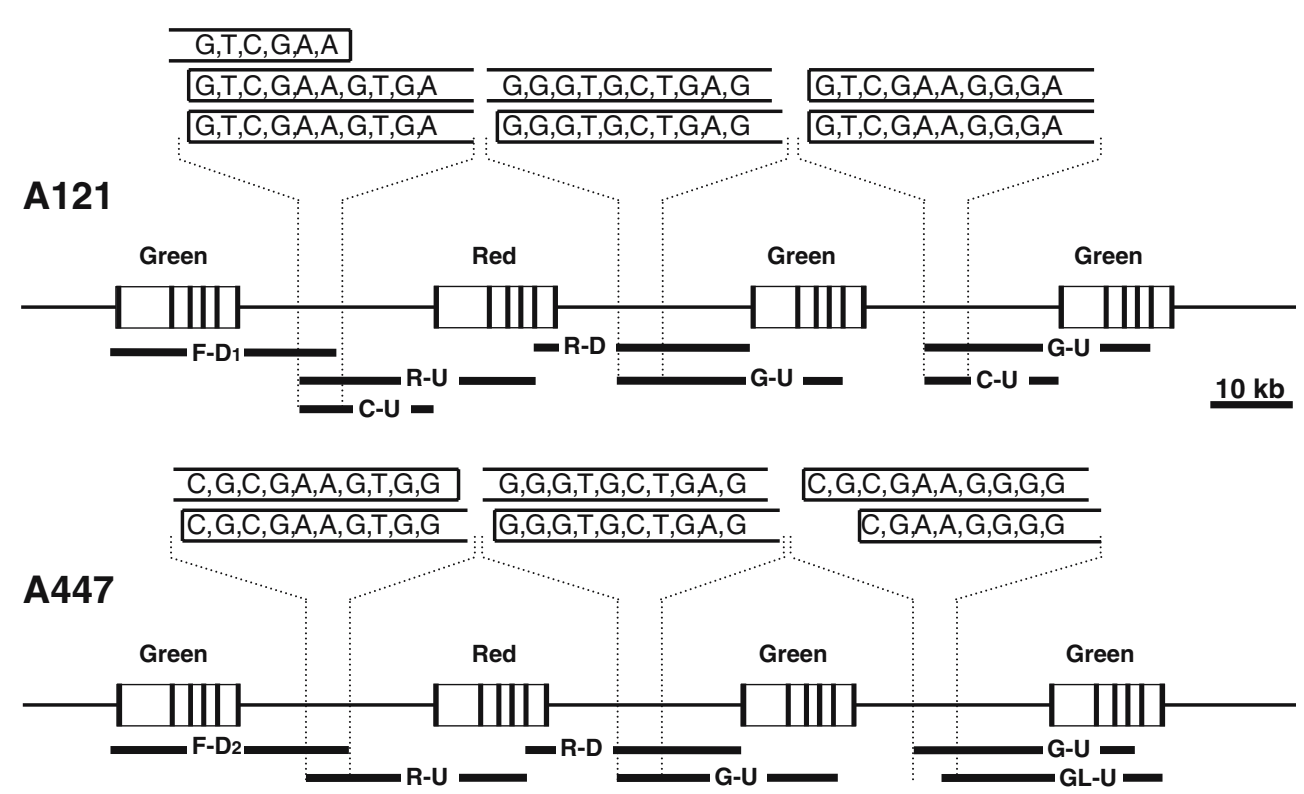

red gene was assessed. Promoter and exons 1-4 in R-U and exon 6 in R-D, including their flanking introns, were sequenced, but no nucleotide substitutions, other than $-71 \mathrm{C}$, were detected in either participant. Exon 5 was amplified using primers $4 \mathrm{RF}$, a specific primer for the red type exon 4 , and $I 5 R$ and sequenced, also including flanking introns 4 and 5 , but no mutations were found. Thus, the red gene in both participants was apparently normal, except at position -71 .

\section{Discussion}

Since the isolation of visual pigment genes by Nathans et al. (1986a), gene arrays in individuals with normal color vision as well as in those with congenital color vision deficiency has been extensively studied (Nathans et al. 1986b; Deeb et al. 1992; Hayashi et al. 1999, 2001; Oda et al. 2000; Jagla et al. 2002; Ueyama et al. 2002, 2003, 2004a, 2004b). Despite these intensive studies, an array with the order of green-red as the first two genes has never been reported. The two participants in this study are the first cases reported to have this type of array. Since both participants had four red/green genes, it was necessary to develop a new strategy for determination of gene order. In this study, we demonstrate that polymorphic sites in the intergenic regions are useful for this purpose.

The two participants were not color-normal, but showed protanomaly, a color vision-deficient phenotype presumed to have green pigment and a spectrally shifted green pigment. Their phenotype may have been caused either by the unique gene order that was reverse to normal or by the A-71C substitution present in the red gene. Alternatively, there may be an as yet unidentified mutation in a tight linkage with the substitution, which we refer as to -71C-linked mutation. We have previously reported that $-71 \mathrm{C}$ in the green gene at the second position was associated with color vision-deficient phenotype in deutan individuals with an apparently normal red-green array (Ueyama et al. 2003). By analogy with these deutan individuals, it may be presumed that $-71 \mathrm{C}$ in the red gene at the second position was associated with the protan color visiondeficient phenotype in A121 and A447. An extensive survey of color-normal males with the gene order of green-red would be needed in the future.

If expression of the red gene is completely repressed either by the reverse order of pigment genes or by a $71 \mathrm{C}$ or $-71 \mathrm{C}$-linked mutation, the expected phenotype is protanopia rather than protanomaly because they have only one type of green pigment in such a condition. In our previous study of 125 protan individuals, 52 participants had either a single green gene array or an array consisting of two identical green genes (Ueyama et al. 2004a). Of the 52 participants 48 showed a full match range of $0-73$, and the other 4 showed broad match ranges of 20-65, 10-70, 0-70, and 0-70, following anomaloscopic examination (Ueyama et al. 2004a). A121 and A447 had narrow match ranges (Table 1) and were distinct from the 52 participants who had only one type of green gene.

Hagstrom et al. (2000) analyzed the expression of red/green pigment mRNA in a single cone cell using four participants. In one male participant, alternating red pigment mRNA was expressed in $15 \%$ of the red 
cones. The participant was presumed to have expressed the alternating red pigment, in addition to the major red pigment and green pigment, in his retina. Their results are in contrast to those of Hayashi et al. (1999), who reported no detection of mRNA expression of the third gene. If we accept the hypothesis that pigment gene expression is not restricted to the first two genes of an array, the protanomaly phenotype in A447 might be explained by a difference in exon 2 between the green gene at the first position and those present downstream (Fig. 1). It has been suggested that exon 2 is important in the green pigment for color discrimination (Neitz et al. 1999; Ueyama et al. 2004a), even though the exon 2-encoded amino acid sequence does not contribute to a spectral shift in the green pigment (Merbs and Nathans 1992; Asenjo et al. 1994). However, A121 had only one type of green gene (Fig. 1), making it difficult to explain his protanomaly phenotype by the expression of the downstream green gene.

Carroll et al. (2002) studied 62 color-normal male individuals for the red:green cone ratio using the flicker photometric electroretinogram. The red:green cone ratio was 0.39-12.42, compatible with published data showing ratios of 0.66-25.0 (Miyahara et al. 1998), 0.9 14.8 (Knau et al. 2002), and 1.1-16.5 (Hofer et al. 2005). These data indicate that red cones exist above a definite degree $(>28 \%)$, but green cones sometimes exist at as low as $4 \%$ in color-normal males. If a good proportion of red cones is necessary for normal color vision, one may speculate that the number of red cones is too small for normal color vision due to either the position of the red gene and/or $-71 \mathrm{C}$ or $-71 \mathrm{C}$-linked mutation of the red gene in A121 and A447. However, the hypothesis is not supported by the fact that colornormal female carriers of protan color vision deficiency have red:green cone ratios as low as 0.09 and 0.03 (Miyahara et al. 1998).

In the human retina each cone has been believed to express only one type of visual pigment (Baylor et al. 1987). Analyses of mRNA expression in single cone cells support this idea (Hagstrom et al. 2000). However, co-expression of blue and green pigments in one cone cell was seen in the mouse, rabbit, and guinea pig systems (Röhlich et al. 1994). In the experiments where the role of a locus control region was assessed using transgenic mice, co-expression of alkaline phosphatase as a reporter of red gene expression and $\beta$-galactosidase as a reporter of green gene expression was seen in $5-35 \%$ of cones (Smallwood et al. 2002). Mutually exclusive expression of blue, red, and green pigments, as suggested in the monkey (Baylor et al. 1987) and human (Roorda and Williams 1999) systems, might not be applicable to some color vision-deficient individuals.
Green and red pigments might be co-expressed in one type of cone and only green pigment in others, leading to protanomaly phenotype, in A121 and A447. This possibility requires confirmation by future studies.

Acknowledgments We would like to express our sincere gratitude to Professor Masahito Ohji (Department of Ophthalmology at Shiga University of Medical Science) for his helpful advice and discussions. We thank Mr Masashi Suzaki (Central Research Laboratory at Shiga University of Medical Science) for his technical help (sequencing and primer extension reactions). This work was supported in part by Grants-in-Aid for Scientific Research from the Ministry of Education, Culture, Sports, Science, and Technology of Japan (14571667, 12770953, and 17791228).

\section{References}

Asenjo AB, Rim J, Oprian DD (1994) Molecular determinants of human red/green color discrimination. Neuron 12:11311138

Baylor DA, Nunn BJ, Schnapf JL (1987) Spectral sensitivity of cones of the monkey Macaca fascicularis. J Physiol 390:145160

Carroll J, Neitz J, Neitz M (2002) Estimates of L:M cone ratio from ERG flicker photometry and genetics. J Vis 2:531-542

Deeb SS, Lindsey DT, Hibiya Y, Sanocki E, Winderickx J, Teller DY, Motulsky AG (1992) Genotype-phenotype relationships in human red/green color-vision defects: molecular and psychophysical studies. Am J Hum Genet 51:687-700

Hagstrom SA, Neitz M, Neitz J (2000) Cone pigment gene expression in individual photoreceptors and the chromatic topography of the retina. J Opt Soc Am A 17:527-537

Hayashi T, Motulsky AG, Deeb SS (1999) Position of a 'greenred' hybrid gene in the visual pigment array determines colour-vision phenotype. Nat Genet 22:90-93

Hayashi S, Ueyama H, Tanabe S, Yamade S, Kani K (2001) Number and variations of the red and green visual pigment genes in Japanese men with normal color vision. Jpn J Ophthalmol 45:60-67

Hofer H, Carrol J, Neitz J, Neitz M, Williams DR (2005) Organization of the human trichromatic cone mosaic. J Neurosci 25:9669-9679

Jagla WM, Jägle H, Hayashi T, Sharpe LT, Deeb SS (2002) The molecular basis of dichromatic color vision in males with multiple red and green visual pigment genes. Hum Mol Genet 11:23-32

Knau H, Kremers J, Schmidt H-J, Wolf S, Wissinger B, Sharpe LT (2002) M-cone opsin gene number does not correlate with variation in L/M-cone sensitivity. Vision Res 42:18881896

Macke JP, Nathans J (1997) Individual variation in the size of the human red and green visual pigment gene array. Invest Ophthalmol Vis Sci 38:1040-1043

Meagher MJ, Jorgensen AL, Deeb SS (1996) Sequence and evolutionary history of the length polymorphism in intron 1 of the human red photopigment gene. J Mol Evol 43:622630

Merbs SL, Nathans J (1992) Absorption spectra of the hybrid pigments responsible for anomalous color vision. Science 258:464-466

Miyahara E, Pokorny J, Smith VC, Baron R, Baron E (1998) Color vision in two observers with highly biased LWS/MWS cone ratios. Vision Res 38:601-612 
Nathans J, Thomas D, Hogness DS (1986a) Molecular genetics of human color vision: the genes encoding blue, green, and red pigments. Science 232:193-202

Nathans J, Piantanida TP, Eddy RL, Shows TB, Hogness DS (1986b) Molecular genetics of inherited variation in human color vision. Science 232:203-210

Neitz J, Neitz M, He JC, Shevell SK (1999) Trichromatic color vision with only two spectrally distinct photopigments. Nat Neurosci 2:884-888

Oda S, Ueyama H, Tanabe S, Tanaka Y, Yamade S, Kani K (2000) Detection of female carriers of congenital color-vision deficiencies by visual pigment gene analysis. Curr Eye Res 21:767-773

Oda S, Ueyama H, Nishida Y, Tanabe S, Yamade S (2003) Analysis of L-cone/M-cone visual pigment gene arrays in females by long-range PCR. Vision Res 43:489-495

Röhlich P, van Veen T, Szél Á (1994) Two different visual pigments in one retinal cone cell. Neuron 13:1159-1166

Roorda A, Williams DR (1999) The arrangement of the three cone classes in the living human eye. Nature 397:520-522

Smallwood PM, Wang Y, Nathans J (2002) Role of a locus control region in the mutually exclusive expression of human red and green cone pigment genes. Proc Natl Acad Sci USA 99:1008-1011
Ueyama H, Kuwayama S, Imai H, Tanabe S, Oda S, Nishida Y, Wada A, Shichida Y, Yamade S (2002) Novel missense mutations in red/green opsin genes in congenital color-vision deficiencies. Biochem Biophys Res Commun 294:205-209

Ueyama H, Li Y-H, Fu G-L, Lertrit P, Atchaneeyasakul L-O, Oda S, Tanabe S, Nishida Y, Yamade S, Ohkubo I (2003) An $-71 \mathrm{C}$ substitution in a green gene at the second position in the red/green visual-pigment gene array is associated with deutan color-vision deficiency. Proc Natl Acad Sci USA 100:3357-3362

Ueyama H, Kuwayama S, Imai H, Oda S, Nishida Y, Tanabe S, Shichida Y, Yamade S (2004) Analysis of L-cone/M-cone visual pigment gene arrays in Japanese males with protan color-vision deficiency. Vision Res 44:2241-2252

Ueyama H, Torii R, Tanabe S, Oda S, Yamade S (2004) An insertion/deletion TEX28 polymorphism and its application to analysis of red/green visual pigment gene arrays. J Hum Genet 49:548-557

Vollrath D, Nathans J, Davis RW (1988) Tandem array of human visual pigment genes at Xq28. Science 240:1669-1672

Winderickx J, Sanocki E, Lindsey DT, Teller DY, Motulsky AG, Deeb SS (1992) Defective colour vision associated with a missense mutation in the human green visual pigment gene. Nat Genet 1:251-256 